\title{
Brugada syndrome: an electrocardiographic diagnosis not to be missed
}

In this issue of Heart we have the opportunity to enjoy the results of a study on sudden cardiac arrhythmic death coming from a group with a longstanding experience in the diagnosis and treatment of this condition. ${ }^{1}$ Since the recognition of the genetically determined disease now known as "Brugada syndrome", ${ }^{2}$ a lot of effort has been dedicated to understanding the pathophysiologic basis and prognosis of this and other primary electrical diseases of the heart. Viskin and colleagues now provide us with an additional and very important piece of information. By comparing a group of patients with the disease to a sufficiently large control group of individuals, they show that the ECG is a powerful tool to recognise patients with this syndrome. Because this disease causes sudden arrhythmic death, the consequences of the diagnosis are very important.

Symptomatic individuals must be protected with an implantable cardioverter defibrillator (ICD). No other proven effective treatment is known. Asymptomatic individuals who carry the disease remain a very difficult problem. At present, we recommend invasive investigation and implantation of an ICD in inducible patients. This is based on the fact that asymptomatic individuals may become symptomatic during follow up, ${ }^{3}$ and also on the observation that many symptomatic individuals have been

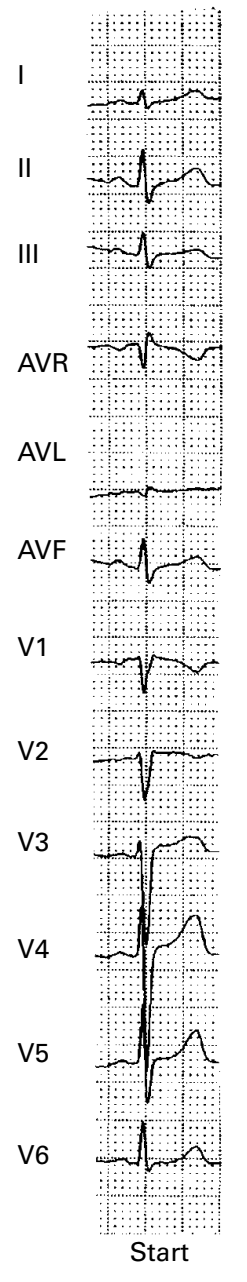

0

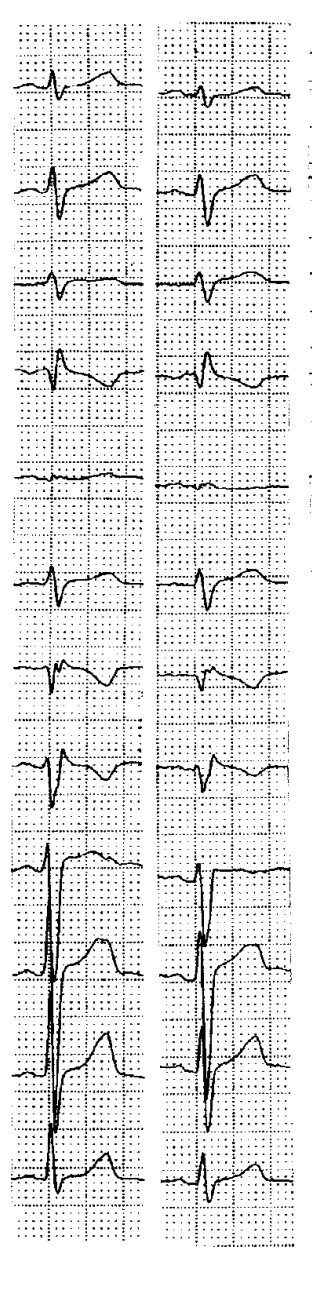

1 '40"

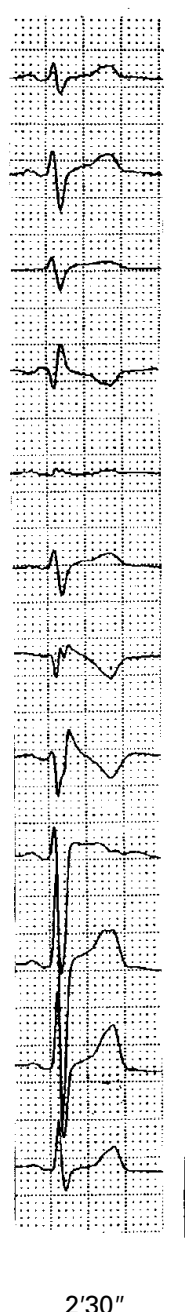

2'30"

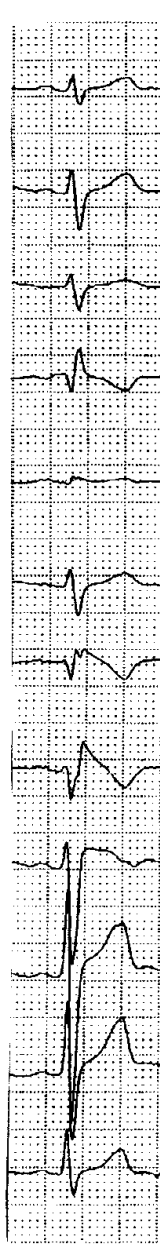

$3^{\prime} 0^{\prime \prime}$

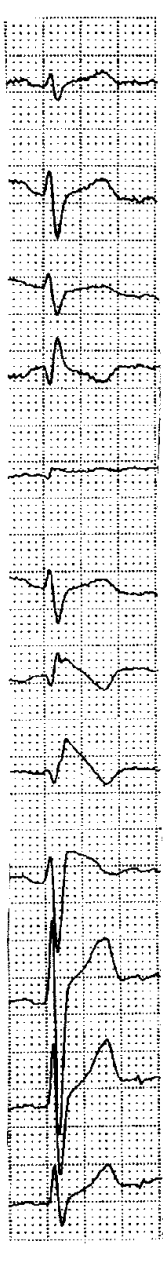

$4^{\prime} 0^{\prime \prime}$

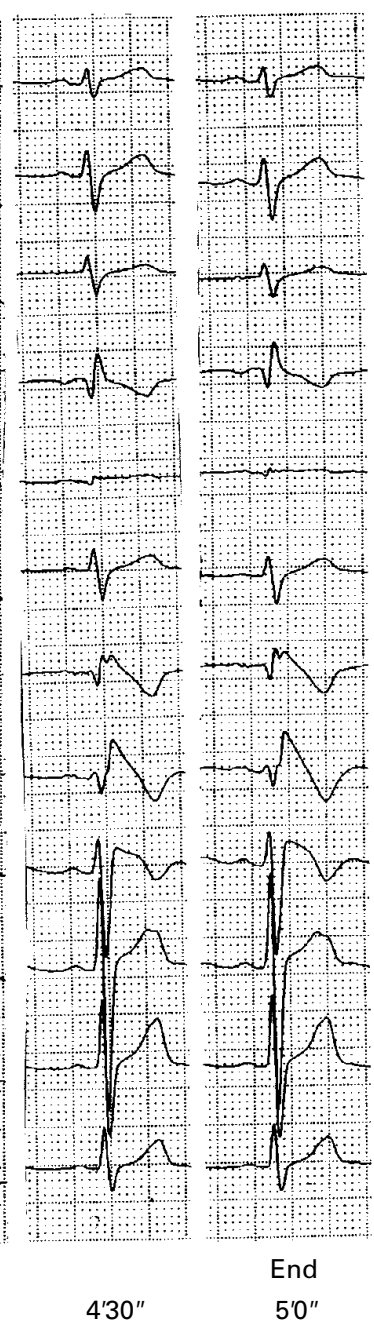

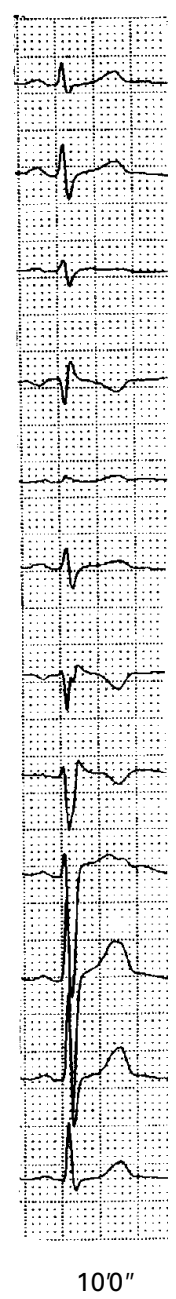

After end

Figure 1 Effects of intravenous administration of $50 \mathrm{mg}$ ajmaline over a five minute period in a patient with the concealed form of the Brugada syndrome. Note the rapid appearance of the typical ECG in leads V1-V3. Ten minutes after stopping the injection the ECG has almost returned to normal. Paper speed $25 \mathrm{~mm} / \mathrm{s}$. 
found to have an abnormal ECG years before the symptoms developed. Thus, whether a patient is classified as symptomatic or asymptomatic seems more a question of the timing of the diagnosis than of the disease itself. Relatives have to be screened for the syndrome. A normal 12 lead ECG is not sufficient to exclude the diagnosis. The individuals have to be screened by means of pharmacologic testing with an intravenous sodium channel blocker like ajmaline (fig 1) or flecainide. The disease is inherited as an autosomal dominant trait in about $30 \%$ of families. In $20 \%$ of cases no clear pattern of inheritance can be defined. The remaining $50 \%$ of cases are sporadic, suggesting a "de novo" mutation (P Brugada, unpublished observations, 2000). Blood samples must be drawn for genetic analysis.

Because of these hereditary aspects, missing the diagnosis in a symptomatic individual also has important consequences. Classifying someone as having "idiopathic" ventricular fibrillation means that family members will not be screened for Brugada syndrome, which may result in medicolegal complications if another (near) sudden death occurs in the family.

The most important conclusion of the study by Viskin and colleagues is, however, that patients with syncope of unknown origin should be pharmacologically tested for Brugada syndrome, a suggestion made by the authors on the basis of their results. ${ }^{1}$ We have long ago incorporated pharmacologic challenge with a sodium channel blocker as one of the studies performed in patients with syncope of unknown cause. The same holds for idiopathic atrial fibrillation, because up to one third of patients with the Brugada syndrome may manifest paroxysmal atrial fibrillation alone or in combination with episodes of ventricular fibrillation. ${ }^{4}$

Whether spontaneously abnormal, or only abnormal after the administration of a sodium channel blocker, a "Brugada ECG" is a marker for sudden cardiac death. This diagnosis should not be missed.

Cardiovascular Center Aalst,

PEDRO BRUGADA

Moorselbaan 164

9300 Aalst, Belgium

email:Pedro.Brugada@pi.be

Supported in part and equally by the Cardiovascular Research and Teaching Institute Aalst, Belgium, the Mapfre Medicine Foundation, Spain, and the Ramon Brugada Senior Foundation, Belgium, Spain, and USA.

1 Viskin S, Fish R, Zeltser D, et al. Prevalence of Brugada sign in idiopathic ventricular fibrillation and healthy controls. Heart 2000;84:31-6.

2 Brugada P, Brugada J. Right bundle branch block, persistent ST segment elevation and sudden death: a distinct clinical and electrocardiographic syndrome. F Am Coll Cardiol 1992;20:1391-6.

3 Brugada J, Brugada R, Brugada P. Right bundle branch block and ST segment elevation in leads V1-V3: a marker for sudden death in patients with no demonstrable structural heart disease. Circulation 1998;97:457-60.

4 Itoh H, Shimizu M, Ino H, et al. Arrhythmic events and ST-segment elevation in Brugada syndrome. 7 Am Coll Cardiol 2000;35:100A.

\section{STAMPS IN CARDIOLOGY}

\section{Hypertension}

The nursing role in the monitoring and measurement of blood pressure is shown on the 60 cent stamp from British Virgin Islands issued in 1983 as part of a four stamp set marking Nursing Week. The 10 cent stamp in this set features Florence Nightingale and the 75 cent stamp Peebles Hospital. The United Nations issue stamps for use on mail posted at their New York, Geneva, and Vienna headquarters. Whereas the stamps from each site share a common theme the designs are frequently very different. Six stamps (two from each site) were issued in 1988 for the International Volunteer Day. The stamps from the UN Headquarters in New York and Geneva featured teaching in various areas including fruit growing and animal husbandry. One of the Vienna HQ stamps carried a health theme showing nursing services and blood pressure measurement.

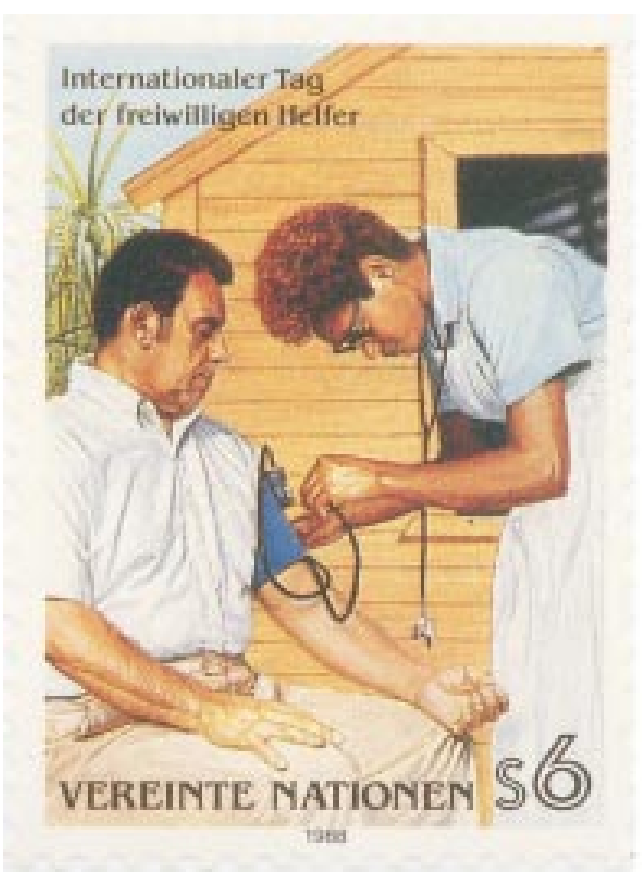

M K DAVIES A HOLLMAN

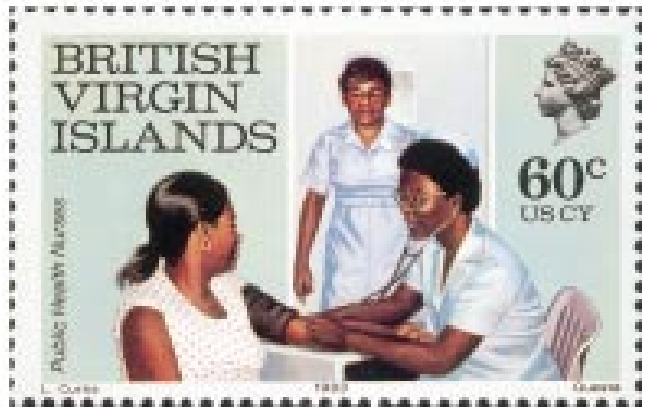




\section{Role of transoesophageal echocardiography in infective endocarditis}

Infective endocarditis continues to be an underdiagnosed and undertreated disease, in spite of a mortality which exceeds that of acute myocardial infarction. In the diagnosis of this disease, echocardiography -including transoesophageal echocardiography — has been a major breakthrough. While the traditional hallmarks of endocarditis were fever together with a new or changed heart murmur, cutaneous signs, and embolic events, echocardiography has enabled the direct visualisation of endocarditic lesions. Indeed, the widely acknowledged Duke criteria for endocarditis ${ }^{1}$ list echocardiographic signs as a major diagnostic criterion, which together with positive blood cultures allows the definite diagnosis of endocarditis (table 1). Recent work indicates that echocardiography should have an even more prominent place, because patients nowadays are very frequently pretreated with antibiotics before any blood cultures are drawn, leading to a high incidence of culture negative endocarditis. ${ }^{2}$

Transthoracic echocardiography detects vegetations with approximately $70 \%$ sensitivity. ${ }^{3}$ The use of transoesophageal echocardiography increases sensitivity and specificity to about $90 \%,{ }^{4-7}$ mainly by detecting small vegetations that escape the transthoracic diagnosis. The diagnostic advantage of transoesophageal echocardiography is even more pronounced in abscesses and prosthetic valves, where transthoracic echocardiography may miss half or more of the lesions. ${ }^{89}$ At the same time, extension of the disease to other valves or to surrounding tissue, valvar defects, chordal rupture, fistulas, and other complications can be diagnosed, the severity of valvar regurgitation and hence hemodynamic stability can be assessed, and size and mobility of vegetations provide a rough estimate of the likelihood of embolism. ${ }^{5}{ }^{11}$ Management decisions, especially the decision to proceed to early surgery, are facilitated by findings such as large vegetations, severe valvar regurgitation, abscess formation, prosthetic valve dehiscence, etc. Conversely, a negative transoesophageal echocardiogram has a negative predictive power of over $90 \%{ }^{12}$ The negative predictive power of a repeated negative transoesophageal echocardiogram after a few days is very high (over 95\%), and is the most convincing clinical way to exclude an endocarditis if there is a clinical suspicion of this disease.

Table 1 The Duke criteria for endocarditis

Diagnosis is:

- definite (by pathology or clinically), possible, or rejected

"Definite" clinical diagnosis by: 2 major, 1 major/3 minor or 5 minor criteria (extremely rare)

Major criteria:

- positive blood culture $(\geqslant 2)$ of typical bacteria

- vegetation, abscess or prosthesis dehiscence on echo

new valvar regurgitation

Minor criteria:

- predisposition, fever, embolic/vascular phenomenon, immunologic signs (including glomerular nephritis, rheumatoid factor, Osler nodes, Roth spots), serology consistent with endocarditis, blood cultures compatible but atypical for endocarditis
In view of this diagnostic potential, should every febrile patient get an echocardiogram, a transoesophageal echocardiogram, or possibly more than one? Apart from the practicality, pretest likelihood considerations indicate that this is not the case. While fever is indeed a very common condition, endocarditis is not a frequent disease. Estimates put the incidence at approximately 14-19 per million persons per year. ${ }^{13}{ }^{14}$ There should therefore be a reasonable degree of suspicion (or pretest likelihood) before sending a patient with fever to the echocardiography laboratory. In practice this means that: (1) other common causes for fever should be clinically unlikely; or (2) the patient should be at risk for endocarditis, such as patients with degenerative valve disease, prosthetic heart valves, immunosuppression, etc; or (3) there should be typical other signs of endocarditis, such as a new heart murmur, cutaneous signs, or embolism.

However, given one or more of the above, there should be no hesitation to proceed from transthoracic to transoesophageal echocardiography if the former is inconclusive. In fact, in most cases even in the presence of a positive transthoracic echocardiogram, an additional transoesophageal study is helpful to reveal the full extent of the disease, especially in the presence of a prosthetic heart valve, in endocarditis not responding promptly to antibiotics, or other complications.

If the suspicion of endocarditis persists and the transoesophageal echocardiogram is negative, the question of a repeat study arises. The best time interval between studies has never been evaluated systematically. Although large vegetations take at least several days to grow, staphylococcal destruction of valves can occur very rapidly. The exact timeframe therefore must be individualised, weighing the risk of overlooking severe disease by postponing a repeat study for too long against the risk of ending up with another false negative or inconclusive study by performing it too early. If the clinical suspicion is rather low, repetition of the study after a week or so seems reasonable.

\section{Have the features of endocarditis changed during recent years?}

The retrospective analysis of Netzer and colleagues in this issue ${ }^{15}$ could not address systematically the utility of echocardiography in general, and transoesophageal echocardiography in particular, owing to its retrospective nature, going back to times before transoesophageal echocardiography was available. It is a chart review of 212 patients hospitalised at their institution with "definite" or "possible" endocarditis according to the Duke criteria, comparing characteristics of the disease in the time intervals 1980-87 and 1988-95. Their findings are mostly, though not completely, in line with our current understanding of this disease.

There are good reasons to believe that the face of infective endocarditis has been changing in recent decades. Presumed factors for this change are: 
- the rise of previously absent risk conditions such as prosthetic valves, immunosuppression, intravenous drug abuse, long term intensive care, and others;

- an aging population with a higher incidence of degenerative valve disease;

- the decline in rheumatic valve disease;

- changes in the spectrum of causative organisms, in particular a shift from Streptococcus viridans to Staphylococcus aureus.

The most frequent causative organisms in both time intervals in the present study were streptococci, although there was a mild increase in staphylococcal endocarditis over time. This is in line with other reports, ${ }^{13}$ although in recent times staphylococcal disease, with its dismal prognosis, is clearly on the rise. ${ }^{16}$ Mortality in this series was relatively low (15\%), which is confirmed by recent estimates from comparable populations $(20 \%$ in the $1980 \mathrm{~s},{ }^{13} 16 \%$ in $1996-8^{16}$ ).

Factors strongly associated with a higher mortality were, among others, age, "neurologic signs" on admission or during the disease course, "fatigue", identification of an abscess on echocardiography, and higher levels of $\mathrm{C}$ reactive protein. These findings are consistent with former reports and not surprising. In contrast, previous studies found a notably worse prognosis for prosthetic valve endocarditis, ${ }^{313}$ possibly owing to the more aggressive causative bacteria (mostly staphylococci). In the present study, however, prosthetic valve endocarditis was not found to be associated with higher mortality. Nevertheless, the high mortality of staphylococcal endocarditis (19\%) was confirmed.

Interestingly, the authors report that in their intravenous drug addicts streptococci were the most frequent causative agents, in strong contrast to previous studies. The authors explain this difference by the Swiss programme of improving hygiene in addicts by education and distribution of sterile needles.

Hence, has infective endocarditis essentially remained the same disease as 20 years ago? That is unlikely. For an adequate interpretation of the present findings, the following possible confounding issues should be kept in mind.

Referral bias - This is not a population based study, and it is unclear how representative for the disease spectrum the patients of this tertiary referral centre were during the two time intervals. It is also not clear whether patients referred directly from outside physicians to cardiac surgery were included in the analysis.

Multiple comparisons and sample size-Many of the differences in table 3 (Factors associated with mortality) in the paper by Netzer and colleagues ${ }^{15}$ are only marginally significant and the level of significance was not corrected for multiple comparisons. Therefore, it is very possible that they do not represent meaningful associations. On the other hand, some differences may be not significant because of small absolute numbers, but still are noteworthy, such as the doubling or tripling of incidence of drug addiction and HIV as underlying conditions. Further, although the paper states a lack of association between mortality and prosthetic valve endocarditis, it elsewhere acknowledges substantially higher mortality in both early $(21 \%)$ and late (24\%) prosthetic valve endocarditis, compared to a native valve endocarditis mortality of $14 \%$. Clearly, the lack of significance here is misleading and should not be construed as evidence against an underlying difference in mortalities.

Case definitions-The authors used the Duke criteria ("possible" or "definite") for diagnosis of infective endocarditis, which are widely accepted. However, the Duke criteria ${ }^{1}$ do not specify minimum requirements for possible endocarditis. "Possible endocarditis" according to this classification implies "findings consistent with infective endocarditis that fall short of 'definite', but not 'rejected"'. The initiators of this classification in their original paper state about patients classified as "possible endocarditis": "This category includes a wide range of indeterminate cases that have very different probabilities of infective endocarditis" and "classification ... into the category of possible endocarditis does not imply that antimicrobial therapy should or should not be given." It is therefore difficult to ascertain which level of confidence that diagnosis of endocarditis carries in this study. In this regard it is also puzzling to see that not only in the early 1980 s, but also in the more recent time periods, in every fifth case the diseased valve could not be identified.

Finally, proving that a difference does not exist between two sets of observations is always harder than finding a "significant" difference. Therefore, the absence of significant differences between the two time intervals does not imply rigorously that there was no such difference. Infective endocarditis, a notoriously protean disease, may in fact be changing its appearance under our noses.

\section{FRANK A FLACHSKAMPF} WERNER G DANIEL

Med Klinik II,

Universität Erlangen-Nürnberg,

Östl.Stadtmauerstr. 29,

D-91054 Erlangen, Germany

email:werner.g.daniel@rzmail.uni-erlangen.de

1 Durack DT, Lukes AS, Bright DK, and the Duke Endocarditis Service. New criteria for diagnosis of infective endocarditis: utilization of specific criteria for diagnosis of infective endocarditis: utilizat
echocardiographic findings. Am $\mathcal{F}$ Med 1994;96:200-22.

2 Habib G, Derumeaux G, Avierinos JF, et al. Value and limitations of the Duke criteria for the diagnosis of infective endocarditis. $\mathcal{F}$ Am Coll Cardiol 1999;33:2023-9.

3 Jaffe WM, Morgan DE, Pearlman AS, et al. Infective endocarditis, 1983-1988: echocardiographic findings and factors influencing morbidity and mortality. F Am Coll Cardiol 1990;15:1227-33.

4 Mügge A, Daniel WG, Frank G, et al. Echocardiography in infective endocarditis: reassessment of prognostic implications of vegetation size determined by the transthoracic and the transesophageal approach. $7 \mathrm{Am}$ Coll Cardiol $1989 ; 14: 631-8$.

5 Mügge A. Echocardiographic detection of cardiac valve vegetations and prognostic implications. Infect Dis Clin N Am 1993;7:877-98.

6 Erbel R, Rohmann S, Drexler M, et al. Improved diagnostic value of echocardiography in patients with infective endocarditis by transesophageal approach. A prospective study. Eur Heart f 1988;9:43-53.

7 Daniel WG, Mügge A. Transesophageal echocardiography. $N$ Engl f Med 1995;332:1268-79.

8 Daniel WG, Mügge A, Martin RP, et al. Improvement in the diagnosis of abscesses associated with endocarditis by transesophageal echocardiography. N Engl f Med 1991;324:795-800.

9 Daniel WG, Mügge A, Grote J, et al. Comparison of transthoracic and transesophageal echocardiography for detection of abnormalities of prosthetic and bioprosthetic valves in the mitral and aortic positions. $A m \mathcal{F}$ Cardiol 1993;71:210-5.

10 Sanfilippo AJ, Picard MH, Newell JB, et al. Echocardiographic assessment of patients with infectious endocarditis: prediction of risk for complications. F Am Coll Cardiol 1991;18:1191-9.

11 Erbel R, Liu F, Ge J, et al. Identification of high-risk subgroups in infective endocarditis and the role of echocardiography. Eur Heart f 1995;16:588602 .

12 Sochowski RA, Chan KL. Implication of negative results on a monoplane transesophageal echocardiographic study in patients with suspected infective endocarditis. F Am Coll Cardiol 1993;21:216-21.

13 van der Meer JTM, Thompson J, Valkenburg HA, et al. Epidemiology of bacterial endocarditis in the Netherlands. I. Patient characteristics. Arch Intern Med 1992;152:1863-8.

14 Nissen H, Nielsen PF, Frederiksen M, et al. Native valve infective endocarditis in the general population: 10-year survey of the clinical picture during the 1980s. Eur Heart $\mathcal{F} 1992 ; 13: 827-7$.

15 Netzer ROM, Zollinger E, Seiler C, et al. Infective endocarditis: the audit of clinical spectrum, presentation and outcome. An analysis of 212 cases 1980-1995. Heart 2000;84:25-30.

16 Benetka O, Block M, Sangha O, et al. On behalf of the ALKK, Arbeitsgemeinschaft Leitender Kardiol.Krankenhausärzte. Clinical course of infective endocarditis in the late nineties: preliminary results of the ALKK endocarditis registry [abstract]. Eur Heart f 1999;20:(suppl):362. 


\section{Fair comparison of mortality data following cardiac surgery}

Outcome based quality of care monitoring is currently the object of a lively debate, particularly in cardiac surgery. Medical, technical, and economical reasons subtend comparisons between surgeons, hospitals, or regions. This raises three major questions. What is the reference to compare with? In what form is information on surgical outcomes disclosed? How are random variations dealt with?

\section{What is the reference to compare with?}

The surgical outcomes of a given centre are compared either to a recognised standard or to other centres' results.

Comparing to a standard, predictive models are used to compute risk adjusted rates: the predicted risk is thus considered as a yardstick for acceptable practice. The Parsonnet scoring system is the most widely used for risk stratification in open heart surgery. The scores were calculated more than 10 years ago (1982-1987) in the USA, and involved over 3500 consecutive surgical procedures. ${ }^{1}$ The system has proved its validity in predicting coronary artery surgery mortality in the UK. ${ }^{2}$ However, it does not seem applicable to the present European practice. Studies carried in the $\mathrm{UK}^{34}$ and France ${ }^{5}$ have shown that current European mortality figures are 30-50\% lower than those predicted by the Parsonnet score. Besides, statisticians criticised the methodology used in the original paper and stated that numerical risks obtained with the Parsonnet index should not be taken literally. ${ }^{6}$

In this issue, Wynne-Jones and colleagues propose a new predictive model based on data concerning all adult patients who underwent cardiac surgery during two years within an area which covers about one eighth of the UK cases. $^{7}$ The observed mortality is $51 \%$ of that predicted by the Parsonnet score and the authors propose a correction factor. This article can be seen as an attempt to establish a modern European standard. As the patient spectrum widens constantly and varies from centre to centre, and as the relation between predictors and outcomes may change or disappear over time, any scoring system should be regularly assessed and updated. ${ }^{8}$

To avoid the problems caused by lack of validity of an external standard, the choice is frequently made to compare performance between institutions. The need to adjust for patient initial status has been strongly argued but this seems to be a difficult task; physicians may search for and note down more medical examination details at large hospitals or at specialised clinics than at small healthcare centres. In such a situation, adjusted comparisons are not valid. The validity of these comparisons depends on the homogeneity of the collection of risk factors. If this condition is met, adjusted comparisons between institutions will be a good alternative to the predicted risk approach.

\section{In what form is information on surgical outcomes disclosed?}

Comparisons can be disclosed under the form of league tables or of prospective monitoring charts.

Most analyses of outcome after cardiac surgery take the form of retrospective investigations and report mortality rates. Average surgical performances over time are delivered to the surgeons or the public as league tables. This choice was recently made in France where, for three consecutive years (1997 to 1999), the lay press has been ranking health institutions according to various criteria and in selected areas, including chiefly heart surgery.

An alternative option is to monitor prospectively the surgical outcomes using a plot to show the difference between the cumulative expected mortality and the deaths that actually occurred. ${ }^{34910}$ Because it shows changes over time, this approach can be used by individual surgeons to monitor their own performance or the progress made in mastering a new technique. ${ }^{10}$

The choice between league tables and prospective monitoring depends on the context, and both methods are useful if the results are appropriately delivered. However, expeditious judgements on quality of care based on indicators or ranks, though more or less conveniently adjusted, must be regarded with extreme caution. Whenever comparisons are to be made between institutions, the following recommendations should be followed: keep the results in their own context, use several indicators rather than just one, and explain the statistical uncertainty. ${ }^{11}$

\section{How are random variations dealt with?}

Random variations can be sufficient to explain occasionally higher or lower death rates in some institutions. This is to be taken into account for both league tables and prospective monitoring charts.

In this issue, Sherlaw-Johnson and colleagues propose a method for assessing the natural variation in outcome. ${ }^{12}$ Their "nested prediction intervals" seem to be easy to generate. A surgeon can use any standard spreadsheet software to generate his own prediction intervals and judge whether poor performance could have occurred by chance. Nevertheless, there is some weakness concerning the power to detect poor performance. Using another statistical method, Poloniecki and colleagues showed that to detect a doubling of death rate with 9/10 chance, 16 expected deaths are required, which is about 160 operations! $!^{4}$ Thus, as stated by Sherlaw-Johnson and colleagues, "a surgeon should certainly not be complacent if mortality figures are poor, but manage to stay within the $95 \%$ limits". Their approach is rather useful to "detect a change, particularly deterioration, as a trigger for further investigation."

The lack of power to detect differences between mortality rates was also mentioned for league tables. Indeed, the ranks of healthcare centres are particularly sensitive to sampling variability and may change broadly from year to year owing to random variability. ${ }^{13}$ Furthermore, this random variability is as wide as the number of patients is low and the number of extrinsic factors is high. Therefore, a moderately active healthcare centre may have a high mortality rate (say $12 \%$ ) one year but $0 \%$ the year before or after, simply because of random variability.

To illustrate this point of view, we reanalysed the data on mortality rates following coronary artery bypass graft surgery in 32 institutions in France. ${ }^{14}$ We recalculated hospital ranks along with their potential errors-credible intervals-according to a statistical method intended to 
Hospitals

Hop. Univ., Strasbourg (551)

St Joseph, Marseille (350)

CHU, St Etienne (335)

Montsouris, Paris (205)

CHU, Rouen (429)

CHU, Tours (249)

CHR, Metz (230)

CHU, Caen (170)

CHU, Montpellier (272)

CHU, Grenoble (328)

St Joseph, Paris (234)

St Laurent du Var (296)

$\mathrm{CHU}$, Angers (255)

CHU, Nice (147)

CHU, Nantes (446)

CHU, Bordeaux (1231)

Le Plessis-Robinson (301)

$\mathrm{CH}$, Mulhouse (262)

$\mathrm{CHU}$, Besancon (240)

$\mathrm{CHU}$, Clermont-Ferrand (357)

La Timone, Marseille (277)

CHU, Lille (666)

CHU, Rennes (636)

CHU, Limoges (346)

CHU, Poitiers (156)

CHU, Amiens (236)

CHU, Brest (144)

CHU, Dijon (346)

CHU, Toulouse (491)

Foch, Suresnes (272)

CHU, Nancy (354)

CHU, Reims (151)

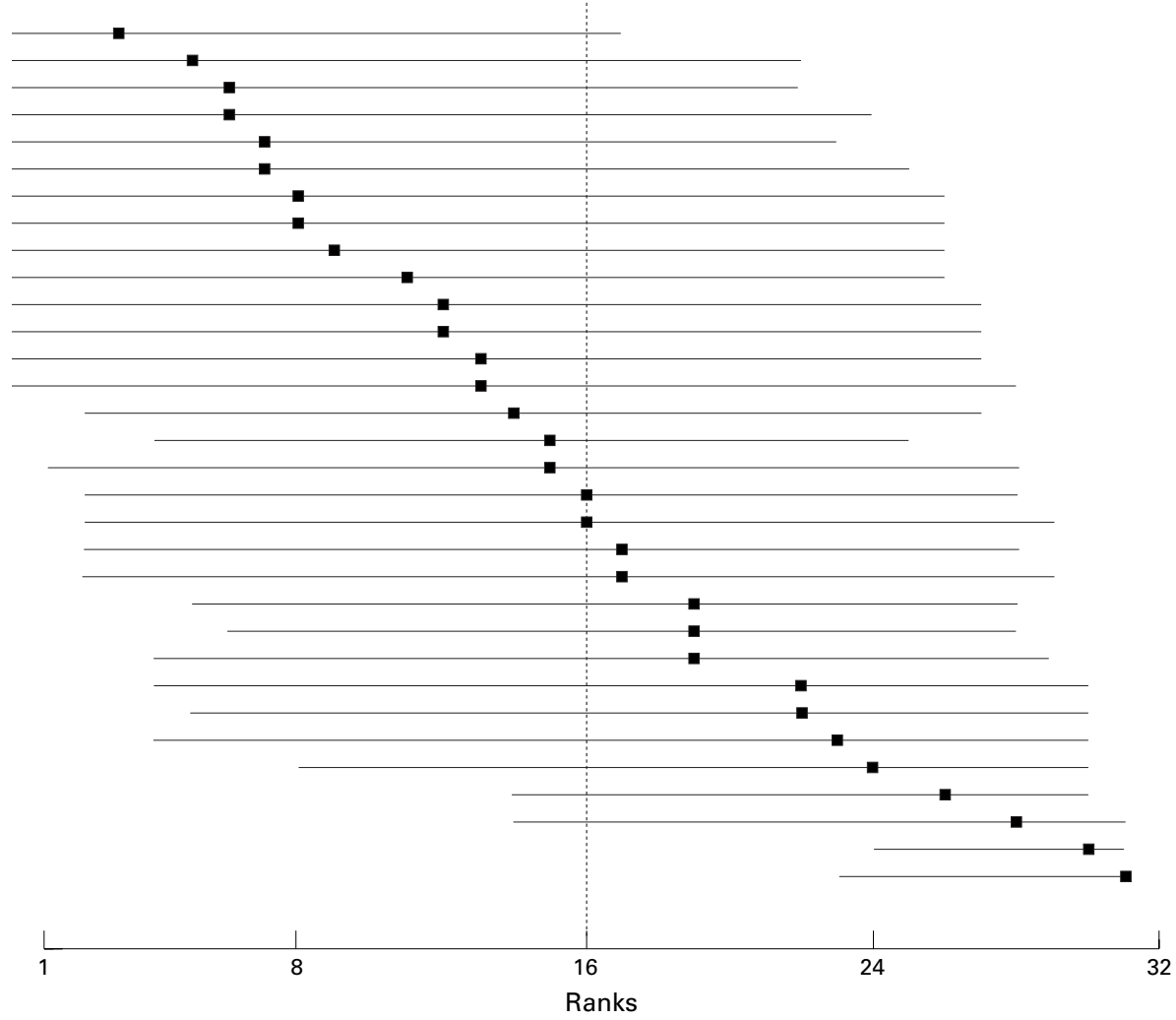

Low mortality

High mortality

Figure 1 Hospital mortality rate ranks (-) following coronary artery bypass grafts, and their 95\% credible intervals ( $\rightarrow$ ) according to our calculations.

evaluate uncertainty associated with ranks. ${ }^{13}$ Figure 1 shows that Mulhouse hospital which ranks 16th (26th in the magazine ${ }^{14}$ ) might have been ranked third or 29 th a year earlier or later by pure chance. We also see that very few hospitals may be singled out as being less or more efficient than any other because the credible intervals are too wide in general, despite the substantial number of cases per centre.

\section{Conclusion}

Any surgeon or centre's performance that departs from a recognised standard should prompt questioning long before approaching confidence limits; it is unacceptable to operate 160 times before being aware of a performance loss. However, comparative results should not be rendered public before significant deviations are observed. Otherwise, the lay opinion may quickly and unfairly judge a given performance as inferior or, more openly, bad. Thus, we recommend that the results of comparisons to a standard or between centres should be considered as incentives for further improvements, rather than tools for final judgements.

Unité de Biostatistique,

R ECOCHARD

Département d'Information Médicale des Hospices Civils de Lyon,

162 avenue Lacassagne,

69424 Lyon Cedex 03, France

rene.ecochard@chu-lyon.fr

G DE GEVIGNEY

Service de cardiologie,

Hôpital cardiologique des Hospices Civils de Lyon,

59 boulevard Pinel,

69500 Bron, France
Unité de Méthodologie en Evaluation Médicale,

C COLIN

Département d'Information Médicale des Hospices Civils de Lyon

Lyon, France

1 Parsonnet V, Dean D, Bernstein AD. A method of uniform stratification of risk for evaluating the results of surgery in acquired adult heart disease. Circulation 1989;79 (suppl 1):1-12.

2 Bridgewater BJM, Neve $\mathrm{H}$, Moat N, et al. Predicting operative risk for coronary artery surgery in the United Kingdom. A comparison of various risk prediction algorithms. Heart 1998;79:350-5.

3 Lovegrove J, Valencia O, Treasure T, et al. Monitoring the results of cardiac surgery by variable life-adjusted display. Lancet 1997;350:1128-30.

4 Poloniecki J, Valencia O, Littlejohns P. Cumulative risk adjusted mortality chart for detecting changes in death rate: observational study of heart surchart for detecting changes in deat
gery. $B M 71998 ; 316: 1697-700$

5 Gabrielle F, Roques F, Michel P, et al. Is the Parsonnet's score a good predictive score of mortality in adult cardiac surgery: assessment by a French multicentre study. Eur f Cardiothorac Surg 1997;11:406-14.

6 Spiegelhalter DJ. Risk stratification of open-heart surgery. BMf 1992;305: 1500 .

7 Wynne-Jones K, Jackson M, Grotte G, et al. Limitations of the Parsonnet score for measuring risk stratified mortality in the north west of England. Heart 2000;84:71-8.

8 Sergeant P, Meyns B. La critique est aisée mais l'art est difficile. Lancet 1997;350:1114-5.

9 De Leval MR, François K, Bull C, et al. Analysis of a cluster of surgical failures: application to a series of neonatal arterial switch operations. F Thorac Cardiovasc Surg 1994;107:914-24.

10 Williams SM, Parry BR, Schlup MMT. Quality control: an application of the cusum. BMF 1992;304:1359-61.

11 Sherlaw-Johnson C, Lovegrove J, Treasure T, et al. Likely variations in perioperative mortality associated with cardiac surgery: when does high mortality reflect bad practice? Heart 2000;84:79-82.

12 Goldstein H, Myers K. Freedom of information: towards a code of ethics for performance indicators. Res Intelligence 1996;July:12-5.

13 Goldstein H, Spiegelhalter DJ. League tables and their limitations: statistical issues in comparisons of institutional performance. $\mathcal{F} R$ Stat Soc Series $A$ 1996;159:385-443.

14 Houdard P, Malye F, Vincent J. Le palmarès des hôpitaux. Science et Avenir 1998;619:32-71. 


\section{Editorial}

\section{Cardiac surgical mortality: the tip of the quality assurance iceberg}

The recent hearings of the General Medical Council and the public inquiry into the "Bristol affair" have fuelled several high profile reports in the media, based on legitimate concerns that cardiac surgery, with its potentially profound adverse outcomes, was devoid of effective quality assurance. Two papers published in this issue of Heart take us one step further in the quest for quality management in cardiac surgery. The first paper from Wynne-Jones and colleagues compares activity and outcomes from four cardiac surgical centres in the north west of England and highlights a number of important issues related to reliable data collection, validation, and risk stratification. ${ }^{1}$ The second paper, by Sherlaw-Johnson and colleagues, simplifies the complex issue of presentation and display of outcome data by adding easily understandable limits to risk adjusted outcome graphs. ${ }^{2}$

The first report describes the highly successful North West Cardiac Surgical Database initiative and demonstrates that where the professional will exists, reliable and meaningful data collection is possible using a variety of data capture models tailored to suit individual institutions. But it is also clear that whichever model is used, support is required from dedicated non-clinical staff to ensure completeness of data collection. One of the key strengths of this initiative has been the rigorous data validation employed across all four centres, and it is therefore pleasing to note that the mortalities quoted for the common adult cardiac surgical procedures are in line with those reported to the UK Cardiac Surgical Register which has been collecting unvalidated activity and mortality data from all National Health Service cardiac surgical units since 1977.

A natural progression from simple activity and mortality data is the collection of a number of variables on each and every patient undergoing surgery to enable stratification for case mix. To this end, the four units have based their dataset on the agreed national dataset of the Society of Cardiothoracic Surgeons, which in turn was based on the US Society of Thoracic Surgeons national database dataset and definitions. ${ }^{3}$ They have deviated from only one definition among the preoperative variables and their adherence to the agreed national dataset and definitions strengthens the UK national initiative. However, even limited deviation raises interesting issues.

No set of definitions will ever be perfect and widespread agreement may require some degree of local compromise in order to ensure that data can be compared between institutions or even internationally. Constructive collaboration of this nature has already been exercised in the UK between the Society of Cardiothoracic Surgeons, the Association of Cardiothoracic Anaesthetists, and the British Cardiovascular Intervention Society to produce a harmonised dataset for the Central Cardiac Audit Database (CCAD). ${ }^{4}$ Similarly, a current initiative to standardise European and North American adult cardiac surgical datasets and definitions is due to report soon. But definitions are an iterative process and without the sort of rigorous analysis used to unravel the apparent different incidences of chronic obstructive airways disease between the participating units, we run the risk of misunderstanding the variables which underpin our risk stratification models. We must therefore be prepared to review and modify existing definitions in concert at appropriate and defined intervals. In time this should improve the quality of contemporary regional and national data, but the price may be a reduction in the value of historical data.

\section{Mortality outcome data}

The authors have limited their outcome data to mortality only. ${ }^{1}$ Reliable postoperative data are the most difficult data to collect and this strategy was wise in the first instance. However, as our appreciation of quality issues and the requirement for evidence based budgeting advances, the value of more comprehensive outcome data to understand "near misses" and to relate preoperative variables to morbidity and resource consumption will become more evident. Furthermore, from the perspective of a patient and his or her family, an accurate explanation of anticipated postoperative morbidity and complications forms an essential part of a courteous and respectful consultation leading to genuinely informed consent.

That the Parsonnet score ${ }^{5}$ is not an accurate predictor of mortality in the north west of England is not surprising. This simple additive scoring system was developed in the USA in the 1980s. Times have changed and the early version, as used by Wynne-Jones, has been largely abandoned in North America for exactly the reasons outlined in their report. ${ }^{1}$ Indeed, the limited applicability of this system to European practice in the 1990 s prompted the development of the EuroSCORE system based on similar methodology. ${ }^{6}$ No scoring system will ever be completely predictive of outcome, particularly in high risk patients, for three reasons. Firstly, we do not yet fully understand the basis of the pathophysiological response to surgery or factors influencing an individual patient's physiological reserve. Secondly, some of the major risk factors are not easily quantifiable or definable and are therefore omitted from most scoring systems. A typical example would be the state of the coronary arteries. To quote Parsonnet, "What may be identified as severe and diffuse disease by one surgeon may be considered relatively routine and non-intimidating by another". ${ }^{4}$ Thirdly, some high risk patients may be difficult to characterise and the statistical denominators are relatively small.

Nevertheless, both the Parsonnet and EuroSCORE models provide a useful yardstick when examining mortality in groups of patients. In general, current UK practice results in a mortality of around half of that predicted by the Parsonnet score, but this will decrease with time-in part because practice is improving and in part because the weighting of the preoperative risk variables changes with time. Indeed, the essence of responsible surgical audit is to understand and attack the most influential risk factors in order to reduce their impact. As a result there is accumulating evidence that the influence of previously important risk factors is being reduced towards the mean. Thus, effective risk modelling must be 
an iterative process; it is this that has prompted the authors to explore an alternative, more contemporary and locally appropriate scoring system.

Sherlaw-Johnson and colleagues use another locally developed model to track mortality trends following cardiac surgery performed by a single surgeon on nearly 400 patients. $^{2}$ The system works somewhat like a bank balance. The operator starts with a zero balance-that is, no operations and no deaths. But with each operation the surgeon is either debited or credited according to the predicted risk of the operation, and at various times the net balance will be either credit, debit or zero. An overall credit implies that more patients have survived than would have been expected and zero balance is exactly what the risk model predicts. ${ }^{7}$ As with most accounts, fluctuations between credit and debit are commonplace and reflect the nature of normal surgical practice. Until now, however, there has been no way of easily knowing when the operator is drifting into the twilight zone of borderline results. Sherlaw-Johnson's article presents us with an objective, statistically based, and easy visual aid for comparing the individual surgeon's variability against that which might be expected for his case mix. This represents a significant step forwards for two reasons. Firstly, this is an extremely difficult issue mathematically, but the authors have used an innovative approach based on pooled data to overcome the difficulties of repeated significance testing. Secondly, the ability to quantify variability in performance will allow us to use variability as a barometer of performance rather than some other arbitrary, rigid value.

\section{Risk models}

Both articles allude to locally developed risk models. We should exercise caution in the construction and interpretation of local risk models and we must understand the balance between an accurate and a useful risk model. An accurate risk model accurately predicts an outcome. At one extreme an accurate local risk model could be constructed using data from a single individual or unit with poor results, reliably predict those results, and then be used to lull the participants into a false sense of security. Although accurate and helpful for predicting local outcome, such a model would have limited value for comparative purposes. A genuinely useful risk model is one that reliably predicts an outcome but is based on, and applicable to, a wider constituency, thereby facilitating reasonable and meaningful comparisons between individuals or units. Local risk modelling has value in that it caters for immeasurable local influences which may not pertain elsewhere. Thus a hierarchy of risk models at different levels, based on single units, several units in a region, along with a nationally based model, will allow accurate local analysis and comparisons while also providing the substrate for dissecting and understanding local variations in the process of surgical care. But again, to be of value, all models should rely on the same definitions for their variables.

The definition of quality in surgery is difficult and was first considered by Florence Nightingale in the UK and Ernst Codman in the USA, but both were ahead of their time and were to some extent ostracised for their efforts which were perceived by some as threatening. ${ }^{8}$ The issue of how to measure quality remains perplexing, but it is an issue which we must grasp if we are to retain the respect and confidence of those we seek to treat. The concept of quality in cardiac surgery should encompass the whole hospital journey, from the time the patient walks through the front door for his or her preliminary assessment to the time of discharge from the postsurgical outpatient clinic and beyond. Individual surgical performance constitutes only a small, albeit important, part of this process.

Surgeon specific mortality data collected by the Society of Cardiothoracic Surgeons clearly indicates that surgeons in the same unit tend to have similar mortalities, highlighting the importance of additional local influences on surgical outcomes. Such influences may include the socioeconomic status of the catchment area, severity of cardiac illness, prevalence of co-morbidities, threshold of referral from both the general practitioner and the cardiologist, threshold of acceptance by the surgeons, standards of anaesthesia, surgery and intensive care, adequacy of facilities and staffing levels, attitude to training, interpersonal relationships between staff, and architectural dispersion within the unit. Any one of these can influence surgical outcome, and it is clear that hospital mortality is not necessarily a measure of overall quality but is simply a rough guide to the success of the surgical episode. An appreciation of quality begins when the patient has recovered from the musculoskeletal insult of surgery and he and his family ask, "was it all worth it?". If the answer is "yes", then added value can be measured by how long the answer remains "yes". A favourable answer to these questions depends as much, if not more, on appropriate referral and acceptance as it does on the technical quality of surgery and postoperative management.

BRUCE E KEOGH

Secretary, Society of Cardiothoracic Surgeons of Great Britain and

Ireland

Coordinator, UK National Adult Surgical Database

Associate Medical Director for Clinical Governance,

University Hospital Birmingham NHS Trust,

Queen Elizabeth Hospital,

Edgbaston, Birmingham B15 2TH, UK

Bruce.Keogh@university-b.wmids.nhs.uk

1 Wynne-Jones K, Jackson M, Grotte G, et al. Limitations of the Parsonnet score for measuring risk stratified mortality in the north west of England. Heart 2000;84:71-8.

2 Sherlaw-Johnson C, Lovegrove J, Treasure T, et al. Likely variations in perioperative mortality associated with cardiac surgery: when does high mortality reflect bad practice? Heart 2000;84:79-82.

3 National Service Framework for Coronary Heart Disease. Modern Standards and Service Models. London: Department of Health, March 2000:24-40.

4 United Kingdom Central Cardiac Audit Database. http:// ccad3.biomed.gla.ac.uk/ccad/

5 Parsonnet V, Dean D, Bernstein A. A method of uniform stratification of risk for evaluating the results of surgery in acquired adult heart disease. risk for evaluating the results of surg
Circulation 1989;79(suppl I):3-12.

6 Nashef SAM, Roques F, Michel P, et al. European system for cardiac operative risk evaluation (EuroSCORE). Eur f Cardiothorac Surg 1999;16:9-13.

7 Lovegrove J, Valencia O, Treasure T, et al. Monitoring the results of cardiac surgery by variable life adjusted display. Lancet 1997;350:1128-30.

8 Spiegelhalter D. Surgical audit: statistical lesson from Nightingale and Codman. F R Statist Soc 1999;162(part 1):45-50. 


\section{Editorial}

\section{Interleukin 6: a message from the heart}

The idea that inflammatory processes are involved in the pathogenesis of atherosclerotic coronary artery disease is not new, ${ }^{1}$ but it has attracted renewed focus recently because of combined clinical, epidemiological, pharmacological, and histological observations. Case-control studies have established consistent associations between circulating inflammatory markers, in particular $C$ reactive protein (CRP), and the subsequent risk of cardiovascular events in healthy people $e^{23}$ and in patients with established coronary heart disease. ${ }^{45}$ CRP concentrations are often increased during acute coronary syndromes and higher concentrations predict a worse outcome in patients with unstable angina. ${ }^{6}$ Indeed, the protective effects of aspirin ${ }^{3}$ and pravastatin $^{5}$ are greatest in patients with the highest baseline CRP concentrations, in keeping with the anti-inflammatory properties of both drug classes, ${ }^{7}$ while angiotensin converting enzyme (ACE) inhibitors also prevent coronary events, probably through anti-inflammatory activity. ${ }^{8}$ The pivotal roles of monocyte derived macrophages and $\mathrm{T}$ lymphocytes as the regulators of matrix degradation, apoptosis, cell replication, and recruitment of circulating cells within the atherosclerotic plaque continue to be elucidated. ${ }^{9}$

\section{Marker of coronary plaque inflammation}

Interleukin 6 (IL-6) has gradually and quietly moved into the spotlight as a local and circulating marker of coronary plaque inflammation. Familiar to rheumatologists, endocrinologists, oncologists, and immunologists, this versatile cytokine is found in large quantities in human atherosclerotic plaques, ${ }^{10}$ typically in macrophage rich areas. ${ }^{8}$ Raised circulating concentrations are found in patients with unstable angina ${ }^{11}$ and in patients at risk of future cardiovascular events. ${ }^{12}$ It can be produced by many vascular cells including endothelial cells, smooth muscle cells, lymphocytes and macrophages ${ }^{13}$ and, being the principal regulator of CRP release from the liver, it plausibly accounts for the link between coronary events and raised circulating CRP concentrations. Interestingly, based on its pleiotropic in vitro behaviour, the net biological effect of IL-6 at the plaque may either be to upregulate or to pacify the inflammatory response, ${ }^{13}$ although the balance of opinion favours the former.

In this issue of Heart, Hojo and colleagues explore links between IL- 6 and restenosis in patients undergoing elective percutaneous transluminal coronary angioplasty (PTCA) for stable angina. ${ }^{14}$ Coronary sinus blood was drawn before and after PTCA and the concentrations of four inflammatory cytokines measured. Of these four, two (monocyte chemoattractant protein 1 and macrophage colony stimulating factor) did not change, one (platelet derived growth factor subtype $\mathrm{AB}$ ) was rarely measurable, but coronary sinus IL- 6 concentrations were significantly raised postprocedure. This release was specific to PTCA rather than diagnostic catheterisation, so common elements of both techniques (peripheral arterial instrumentation, coronary arterial and coronary sinus catheterisation, administration of contrast agents) were unlikely to be the stimulants of IL-6 release. It also arose from the heart in that IL- 6 concentrations were not raised in peripheral arterial blood samples taken at the same time. The authors performed six month follow up coronary angiography and found that the late loss index (an angiographic measure of restenosis) correlated with the increase in IL-6 concentration after PTCA. The strength of the relation is not strong: between a oneand twofold increase (most patients) no clear correlation is visible, although all patients who had more than a twofold rise had a high late loss index, and patients who had no or minimal IL-6 increases had minimal late loss at follow up. Patients who fulfilled binary criteria for restenosis had more post-PTCA IL-6 release than those who did not.

\section{Novel features of this study}

Previous workers have measured IL-6 concentrations after PTCA, but one of the novel features of the present study is that IL-6 release was consistently detected in patients after PTCA of clinically stable lesions. Post-PTCA IL-6 release has been demonstrated in patients with unstable angina ${ }^{15}$ and acute myocardial infarction, ${ }^{16}$ although in neither study could it be detected in patients with stable angina. The use of a more sensitive IL-6 assay in the present study (stated lower limit of detection $0.1 \mathrm{pg} / \mathrm{ml}$ as compared with $3.0 \mathrm{pg} / \mathrm{ml}^{15}$ and $2.0 \mathrm{pg} / \mathrm{ml}^{16}$ ) accounts for these disparities, and the authors have maximised their capacity to detect subtle cardiac IL-6 release by sampling coronary sinus blood. We do not know whether the source of this IL-6 is predominantly circulating leucocytes, adherent leucocytes or cells contained within the plaque, although the nature of PTCA associated trauma suggests that it is likely to be the latter.

That the magnitude of inflammatory marker release may also predict restenosis after PTCA and stenting is an attractive theory that is raised but not proven by the present study. It is supported by observations that serum amyloid A release is common post-PTCA and that it predicts restenosis in patients with unstable angina, ${ }^{17}$ and that raised plasma concentrations of soluble intercellular adhesion molecule-1 (sICAM-1) predict restenosis after PTCA for acute myocardial infarction. ${ }^{18}$ The failure of a long list of anti-inflammatory drugs to prevent restenosis may indicate that inflammation is a marker rather than a cause of restenosis, that the agents tested have not been sufficiently specific or that inappropriate components of the inflammatory system were targeted. Exciting recent animal studies suggest that inhibition of leucocyte adhesion via the Mac-1 integrin receptor substantially attenuates post-PTCA and post-stenting restenosis, ${ }^{19}$ paving the way for clinical trials of Mac-1 receptor blockers to prevent restenosis.

The designation of atherosclerosis as a chronic inflammatory or autoimmune process, much like rheumatoid arthritis or pulmonary fibrosis, represents an exciting and logical paradigm shift for cardiologists. Plasma concentrations of IL-6 and its hepatic byproduct CRP appear to reflect the intensity of occult plaque inflammation and by inference may grade vulnerability to rupture, ${ }^{20}$ a concept supported by the fact that the population risk of acute cardiovascular events is predicted by their ambient circulating concentrations. ${ }^{2-5} 12$ Potential consequences include population screening for circulating inflammatory markers, recommendation of anti-inflammatory treatment 
(aspirin, HMG-CoA reductase inhibitors or ACE inhibitors) for those thought to be at higher risk, and the use of CRP rather than low density lipoprotein assays to guide dosing of HMG-CoA reductase inhibitor treatment. ${ }^{21}$ If fibrinolytic agents dominated the $1980 \mathrm{~s}$ and platelet directed drugs ruled the 1990 s, the next decade may well see effective leucocyte modulating therapy as a new cornerstone of cardiovascular treatment.

Interventional Cardiology,

NIALL A HERITY

Stanford University Medical Center,

300 Pasteur Drive,

Stanford CA 94305, USA

email: niall@leland.stanford.edu

1 Ross R. The pathogenesis of atherosclerosis-an update. $N$ Engl f Med 1986;314:488-500

2 Kuller LH, Tracy RP, Shaten J, et al. Relation of C-reactive protein and coronary heart disease in the MRFIT nested case-control study. Am F Epidemiol 1996;144:537-47.

3 Ridker PM, Cushman M, Stampfer MJ, et al. Inflammation, aspirin, and the risk of cardiovascular disease in apparently healthy men. $N$ Engl $\mathcal{F}$ Med 1997;336:973-9.

4 Haverkate F, Thompson SG, Pyke SD, et al. Production of C-reactive protein and risk of coronary events in stable and unstable angina. Lancet 1997; 349:462-6.

5 Ridker PM, Rifai N, Pfeffer MA, et al. Inflammation, pravastatin, and the risk of coronary events after myocardial infarction in patients with average cholesterol levels. Circulation 1998;98:839-44.

6 Liuzzo G, Biasucci LM, Gallimore JR, et al. The prognostic value of Liuzzo G, Biasucci LM, Gallimore J et al. The prognostic value of
C-reactive protein and serum amyloid A protein in severe unstable angina. C-reactive protein and serum amylo

7 Vaughan CJ, Murphy MB, Buckley BM. Statins do more than just lower Vaughan CJ, Murphy MB, Buckley BM.
cholesterol. Lancet 1996;348:1079-82.
8 Schieffer B, Schieffer E, Hilfiker-Kleiner D, et al. Expression of angiotensin II and interleukin 6 in human coronary atherosclerotic plaques. Potential implications for inflammation and plaque instability. Circulation 2000;101: 1372-8.

9 Ross R. Atherosclerosis—an inflammatory disease. $N$ Engl f Med 1999;340: $115-26$.

10 Rus HG, Vlaicu R, Niculescu F. Interleukin-6 and interleukin-8 protein and gene expression in human arterial atherosclerotic wall. Atherosclerosis 1996; 127:263-71.

11 Biasucci LM, Vitelli A, Liuzzo G, et al. Elevated levels of interleukin-6 in unstable angina. Circulation 1996;94:874-7.

12 Ridker PM, Hennekens CH, Buring JE, et al. C-reactive protein and other markers of inflammation in the prediction of cardiovascular disease in women. N Engl f Med 2000;342:836-43.

13 Lotz M. Interleukin-6. Cancer Invest 1993;11:732-42.

14 Hojo Y, Ikeda U, Katsuki T, et al. Interleukin-6 expression in coronary circulation after coronary angioplasty as a risk factor for restenosis. Heart 2000;84:83-7.

15 Liuzzo G, Buffon A, Biasucci LM, et al. Enhanced inflammatory response to coronary angioplasty in patients with severe unstable angina. Circulation 1998;98:2370-6.

16 Neumann FJ, Ott I, Gawaz M, et al. Cardiac release of cytokines and inflammatory responses in acute myocardial infarction. Circulation 1995;92:748-55.

17 Blum A, Vardinon N, Kaplan G, et al. Autoimmune and inflammatory responses may have an additive effect in postpercutaneous transluminal coronary angioplasty restenosis. Am f Cardiol 1998;81:339-41.

18 Kamijikkoku S, Murohara T, Tayama S, et al. Acute myocardial infarction and increased soluble intercellular adhesion molecule-1: a marker of vascular inflammation and a risk of early restenosis? Am Heart f 1998;136:2316.

19 Rogers C, Edelman ER, Simon DI. A mAb to the beta2-leukocyte integrin Mac-1 (CD11b/CD18) reduces intimal thickening after angioplasty or stent implantation in rabbits. Proc Natl Acad Sci U S A 1998;95:10134-9.

20 Davies MJ. The pathophysiology of acute coronary syndromes. Heart 2000; 83:361-6.

21 Ridker PM, Rifai N, Pfeffer MA, et al. Long-term effects of pravastatin on plasma concentration of C-reactive protein. Circulation 1999;100:230-5.

\section{IMAGES IN CARDIOLOGY}

\section{Saddle pulmonary embolism: diagnosis by spiral computed tomography}

A 62 year old man presented with a two week history of dyspnoea on minimal exertion. His medical history was significant for stage IV pancreatic adenocarcinoma and nonHodgkin's lymphoma. An admitting chest roentgenogram revealed a large left pleural effusion and evidence of bilateral hilar adenopathy. Following a left sided therapeutic thoracocentesis, there was no improvement in his symptoms. Spiral computed tomography of the thorax showed a saddle pulmonary embolus astride the main pulmonary trunk. Also noted incidentally in the figure is bilateral hilar adenopathy and pleural effusions.

ASHISH PERSHAD TIMOTHY J BYRNE

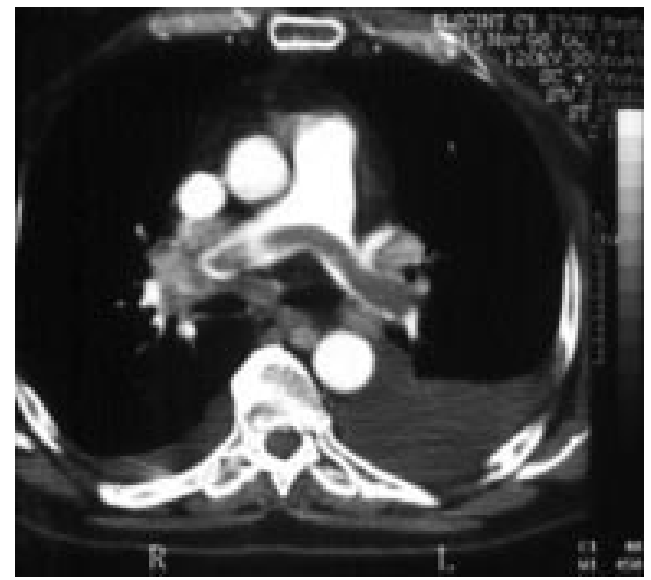




\section{Editorial}

\section{Treatment options for coarctation of the aorta}

Surgical treatment for coarctation was introduced over 50 years ago and has steadily been refined, with particular improvements in results over the last 10 years or so. Balloon angioplasty was introduced in the mid 1980s, initially for recoarctation and later for unoperated ("native") coarctation. In this issue Thanopoulos and his colleagues from Athens report their favourable early experience of stent implantation to treat coarctation or recoarctation in a small group of children and adolescents. ${ }^{1}$ Many factors should be taken into account when deciding upon the best treatment for a patient with coarctation including age, coarctation morphology, whether previous surgery has been undertaken, and local institutional results of each type of treatment. Unfortunately there are no clinical trials of appropriate size or design upon which to base an objective judgement of the optimum form of treatment, but it is helpful to compare approximately contemporary studies of surgery, balloon angioplasty, and stent implantation.

\section{Surgery}

The major complications of surgery are death, paraplegia caused by perioperative spinal cord ischaemia, recurrent or residual coarctation, and late aneurysm formation at the site of the repair. There are also late complications related to the coarctation itself including hypertension, dissecting, diffuse or false aneurysm of the aorta, stroke, and early coronary artery disease. In a large (571 patients) long term study from the Mayo clinic, ${ }^{2}$ estimated survival at 10, 20, and 30 years was $91 \%, 84 \%$, and $76 \%$, respectively. Late deaths were most commonly related to coronary artery disease followed by sudden death, heart failure, stroke, and rupture of aortic aneurysm. Young age at operation favourably influenced outcome, but the risk of late death increased the higher the postoperative resting blood pressure. A similar effect of postoperative hypertension on long term outcome was reported in other studies from the $\mathrm{UK}^{3}$ and from mainland Europe. ${ }^{4}$ The great influence of postoperative upper limb hypertension on long term survival emphasises the extreme importance of optimum relief of aortic obstruction, whatever the mode of treatment and whatever the age of the patient.

Three types of surgical repair remain in common use: resection of the stenosed segment of aorta with end to end anastomosis; use of a subclavian flap; and patch aortoplasty (using synthetic material for the patch). The choice of operative technique is influenced by the morphology of the coarctation, the age of the patient, and the personal preference of the surgeon, although among surgeons specialising in congenital heart disease end to end anastomosis has become the most popular option as it probably provides the best anatomical relief of obstruction, has the lowest risk of recoarctation, and probably has the lowest incidence of late aneurysm formation. ${ }^{5}$

The major stimuli behind the introduction of therapeutic cardiac catheterisation for the treatment of coarctation were the risk of residual or recurrent coarctation and the rare but catastrophic spinal cord infarction following surgical treatment. Recoarctation (in reality a mixture of residual and recurrent coarctation) occurs in approxi- mately $10 \%$ of cases in most published surgical series up until the early 1990s, but in the last decade refinement of the end to end anastomosis can result in a reduction in recoarctation to less than $4 \%,{ }^{6}$ an experience similar to that of my own centre, where (excluding preterm babies) there has been $0.5 \%$ reintervention for recoarctation in children and adults operated upon during the last 10 years (unpublished observation). Aortic aneurysm appears to be extremely rare early after end to end anastomosis but it is not yet clear whether modern surgery will reduce the incidence of late aneurysm formation. The risk of paraplegia is probably in the region of $1 \%$ in unselected cases, but is higher in patients who have a paucity of collateral vessels around the coarctation.

\section{Balloon angioplasty}

Balloon angioplasty equipment has improved steadily since the early 1980s (smaller catheters and lower profile, higher pressure balloons) and the technique has been refined too, particularly with regard to choice of inflated balloon diameter. It is generally considered safer in patients with postsurgical recoarctation (because of the supporting effect of surrounding scar tissue) rather than native coarctation, although a large US angioplasty registry found similar acute relief of obstruction in both groups. ${ }^{7}$ The registry received data on 970 procedures and reported a $0.7 \%$ mortality regardless of whether previous surgery had been undertaken or not. A "suboptimal" result was reported in $19 \%$ of patients with native coarctation and $25 \%$ of patients with recoarctation.

Results of balloon angioplasty are much less favourable in neonates and infants, presumably related to constriction of ductal tissue; a comparison in the early 1990s of pooled results from both surgery and balloon angioplasty in infancy ${ }^{8}$ suggested an overall incidence of recoarctation of $14 \%$ after surgery and $57 \%$ after angioplasty. Long segment stenoses are less likely to respond to balloon dilatation than discrete coarctation. In one study of 90 procedures for recoarctation the diameter of the transverse aortic arch was an important predictor of successful reduction in pressure gradient, but even after an initially "optimal" result only $72 \%$ of patients remained free from reintervention over a period of 12 years. ${ }^{9}$ Also of note were two procedure related major neurological complications among the 90 patients, illustrating that neurological damage is not isolated to surgical treatment.

Aneurysm formation, occurring immediately or within a few years, has been reported to occur after $5-20 \%$ of coarctation angioplasty, ${ }^{10}{ }^{11}$ but the incidence of late aneurysm is still unknown. Acute catastrophic aortic rupture, sometimes fatal, has also been reported occasionally, with one report raising the possibility that previous patch aortoplasty might increase the risk of rupture. ${ }^{12}$ The relatively high incidence of aneurysms after angioplasty is, perhaps, predictable in the light of studies demonstrating the mechanism of action of balloon dilatation of coarctation; both histology ${ }^{13}$ and intravascular ultrasound ${ }^{14}$ suggest that enlargement of the aortic lumen is a result of tearing of the intima and media, that only the adventitia may be left 
intact, and that dissection or intimal flaps are the rule rather than the exception. Even when there is no obvious angiographic evidence of aneurysm formation, ballooned coarctation segments later resected at surgery show an absence of muscle and elastic lamella strongly suggesting that the substrate for late aneurysm formation is present. ${ }^{15}$ In the only randomised trial to date of surgery and balloon angioplasty for native coarctation there were $20 \%$ aneurysms visible on angiography after angioplasty compared to none after surgery. ${ }^{11}$

In young children there are additional concerns about vascular damage related to the introduction of relatively large balloon catheters. Magnetic resonance imaging of the femoral and iliac arteries has shown arterial stenosis or occlusion in $39 \%$ of cases in one study ${ }^{16}$ and in some cases the changes were progressive. Symptoms of limb ischaemia appear to be very rare in childhood, but such vascular damage might well prove to be important in adult life.

\section{Are adults different?}

Adults pose a slightly different dilemma; recoarctation after an initially good result with balloon angioplasty and vessel damage related to arterial access are both rare, so aneurysm formation, aortic rupture, and incomplete relief of obstruction are the major factors to be taken into account. Aneurysms have been reported to occur after angioplasty in $7-13 \%$ of adults, ${ }^{17-19}$ sometimes requiring urgent surgical treatment. The risk of acute aortic rupture or dissection is probably no different in adults and children. Most small aneurysms do not seem to get larger in the currently limited experience of follow up, ${ }^{17}$ but it would seem reasonable to view any aneurysm with concern. There is limited data on incomplete relief of aortic obstruction for angioplasty in adults, but in the largest study (of children and adults) to date greater age was a significant independent risk factor for a suboptimal result.

\section{Stent implantation}

With simple balloon dilatation of the aorta some degree of elastic recoil is common after balloon deflation; it may be necessary to use a balloon which is larger than the desired final diameter of the aortic lumen. This "overstretching" of the coarctation is thought to be a factor which increases the risk of aneurysm, rupture, and dissection. Stent implantation prevents elastic recoil (potentially allowing the use of slightly smaller balloons) and might, in theory, reduce these risks.

Thanopoulos and colleagues ${ }^{1}$ used balloon expandable stents in the treatment of coarctation in 17 patients aged between 5 months and 15 years, adding to others' early experience. $^{20-23}$ These series include a total of 97 patients, some with unoperated coarctation and some with recoarctation. In most patients satisfactory relief of aortic arch gradient was achieved, and the pooled risk of acute aneurysm formation was just over $3 \%$. It is too early to know the implications of small acute aneurysms or the incidence of late aneurysm formation, or whether stenting reduces the risk of aneurysm. What is clear from these early studies is that while stenting might reduce aortic overstretching, it does not eliminate aneurysm formation. There is very little experience of covered stents so far; they may be used to treat aneurysms ${ }^{24}$ and might reduce the risk of aneurysm within the stented segment of aorta, but will not prevent aortic tears at the sharp ends of the stent.

Some degree of restenosis caused by endothelial proliferation occurred in $27 \%$ of patients in the largest of these studies ${ }^{21}$ over a maximum follow up period of 25 months. There must be additional concerns over stent implantation in children in whom growth alone will necessitate stent redilatation. A few patients in the above studies have had stents redilated successfully. Animal studies of aortic stent redilatation have had mixed results, with one favourable experience ${ }^{25}$ but another ${ }^{26}$ inducing fatal aortic rupture in nearly a third of cases.

\section{What's best?}

There is widespread agreement that therapeutic catheterisation sometimes has a place in the increasingly rare patient with postsurgical recoarctation at any age. For native coarctation it is apparent that different specialist centres take very different views on the best form of treatment, raising interesting and important issues regarding informed consent. In the absence of available late follow up data for therapeutic catheterisation, informed consent must be based upon an explanation of the differences in early results of treatment.

The hope that angioplasty would avoid the neurological damage occasionally associated with surgery has not been fulfilled, and it seems unlikely that the small risks of spinal cord injury with surgery and stroke with therapeutic catheterisation will prove to be statistically different. Available data suggest that acute relief of aortic obstruction, freedom from reintervention for recoarctation or residual coarctation, and freedom from aortic tears are all better with surgical treatment. These differences are most striking in infants, still clearly evident in older children, and present but less pronounced in adults. In adults there appears to be a slightly lower chance of immediate complete relief of aortic obstruction with angioplasty than there is in children-a serious cause for concern in the light of the major effect of postoperative hypertension on long term outcome. There is additional theoretical concern that surgical treatment following inadequate angioplasty may carry an increased risk of spinal cord damage because collaterals will regress after partial relief of obstruction. ${ }^{15}$ Stenting does not eliminate the risk of aneurysm, aortic rupture or dissection, but it is not clear yet whether these risks are lower than with angioplasty alone. Even if the unknown long term significance of the common finding of some degree of intimal proliferation after stenting is disregarded, it seems wise to avoid stent implantation in children if at all possible as there will be an almost inevitable need for reintervention as the child grows.

Department of Paediatric Cardiology,

JOHN L GIBBS

Yorkshire Heart Centre,

E Floor, fubilee Wing,

Leeds General Infirmary,

Great George Street,

Leeds LS1 3EX, UK

email:jgibbs@cwcom.net

1 Thanopoulos VD, Hadjinikolaou L, Georgia N, et al. Stent treatment for coarctation of the aorta: intermediate-term follow up and technical considerations. Heart 2000;84:65-70.

2 Cohen M, Fuster V, Steele PM, et al. Coarctation of the aorta. long term follow up and prediction of outcome after surgical correction. Circulation low up and pre

3 Bobby JJ, Emami JM, Farmer RDT, et al. Operative survival and forty year follow up of surgical repair of aortic coarctation. Br Heart $f$ 1991;65:2716.

4 Koller M, Rothlin M, Senning A. Coarctation of the aorta: review of 362 operated patients. Long term follow up and assessment of prognostic variables. Eur Heart f 1987;8:670-9.

5 Knyshov GV, Sitar LL, Glagola MD, et al. Aortic aneurysms at the site of repair of coarctation of the aorta: a review of 48 patients. Ann Thorac Surg 1996;61:935-9.

6 Backer CL, Mavroudis C, Zias EA, et al. Repair of coarctation with resection and extended end-to-end anastomosis. Ann Thorac Surg 1998;66:1365-70.

7 McCrindle BW, Jones TK, Morrow WR, et al. Acute results of balloon angioplasty of native coarctation versus recurrent aortic obstruction are equivalent. Valvuloplasty and Angioplasty of congenital anomalies (VACA) equivalent. Valvuloplasty and Angioplasty of congenital
registry investigators. $7 \mathrm{Am}$ Coll Cardiol 1996;28:1810-7.

8 Johnson MC, Canter CE, Strauss AW, et al. Repair of coarctation of the aorta in infancy: comparison of surgical and balloon angioplasty. Am Heart

9 Yeltman AT, Nykanen D, McCrindle BW, et al. Balloon angioplasty of recurrent coarctation: a 12 year review. $\mathcal{F}$ Am Coll Cardiol 1997;30:811-6. 
10 Rao PS, Galal O, Smith PA, et al. Five- to nine-year follow up results of balloon angioplasty of native coarctation in infants and children. $7 \mathrm{Am}$

11 Shaddy RE, Boucek MM, Sturtevant JE, et al. Comparison of angioplasty and surgery for unoperated coarctation of the aorta. Circulation 1993;87:793-9.

12 Balaji S, Oommen R, Rees PG. Fatal aortic rupture during balloon dilatation of recoarctation. Br Heart $\mathcal{F} 1991 ; 65: 100-1$

13 Ho SY, Somerville J, Yip WC, et al. Transluminal balloon dilatation of resected coarcted segments of thoracic aorta: histological study and clinical implications. Int $\mathcal{F}$ Cardiol 1988;19:99-105.

14 Ino T, Kishiro M, Okubo M, et al. Dilatation mechanism of balloon angioplasty in children: assessment by angiography and intravascular ultrasound. Cardiovascular \& Interventional Radiology 1998;21:102-8.

15 Brandt B, Marvin WJ, Rose EF, et al. Surgical treatment of coarctation of the aorta after balloon angioplasty. F Thorac Cardiovasc Surg 1987;94:715-9. 16 Burrows PE, Benson LN, Babyn P, et al. Magnetic resonance imaging of the iliofemoral arteries after balloon dilatation angioplasty of aortic arch
obstructions in children. Circulation 1994;90:915-20.

17 Fawzy ME, Sivanandam V, Galal O, et al. One- to ten-year follow up results of balloon angioplasty of native coarctation of the aorta in adolescents and adults. F Am Coll Cardiol 1997;30:1542-6.

18 Tyagi S, Arora R, Kaul UA, et al. Balloon angioplasty of native coarctation of the aorta in adolescents and young adults. Am Heart $\mathcal{F}$ 1992;123:674-80.
19 Phadke K, Dyet JF, Aber CP, et al. Balloon angioplasty of adult coarctation. Br Heart F 1993;69:36-40.

20 Ebeid MR, Prieto LR, Latson L. Use of balloon-expandable stents for coarctation of the aorta: initial results and intermediate-term follow-up. $\mathcal{F}$ Am Coll Cardiol 1997;7:1847-52.

21 Suarez de Lezo J, Pan M, Romero M, et al. Immediate and follow-up findings after stent treatment for severe coarctation of aorta. Am $\mathrm{f}$ Cardiol 1999;83:400-6.

22 Bulbul ZR, Bruckheimer E, Love JC, et al. Implantation of balloonexpandable stents for coarctation of the aorta: implantation data and short term results. Catheterization \& Cardiovascular Diagnosis 1996;39:36-42.

23 Magee AG, Brzezinska-Rajszys G, Qureshi SA, et al. Stent implantation for aortic coarctation and recoarctation. Heart 1999;82:600-6.

24 Gunn J, Cleveland T, Gaines P. Covered stent to treat co-existent coarctation and aneurysm of the aorta in a young man. Heart 1999;82:351.

25 Morrow WR, Smith VC, Ehler WJ, et al. Balloon angioplasty with stent implantation in experimental coarctation of the aorta. Circulation 1994;89: 2677-83.

26 Mendelsohn AM, Dorostkar PC, Moorehead CP, et al. Stent redilatation in canine models of congenital heart disease: pulmonary artery stenosis and coarctation of the aorta. Catheterization $\mathcal{E}$ Cardiovascular Diagnosis 1996;38:430-40.

\section{IMAGES IN CARDIOLOGY}

\section{Mitral regurgitation secondary to ruptured papillary muscle}

A 68 year old man presented with an acute non-Q wave anterolateral myocardial infarction. He initially made an uneventful recovery. On day 6 postinfarction he developed sudden onset pulmonary oedema with associated hypotension. He required immediate intubation and despite high level inotropic support he remained hypotensive. A systolic murmur was noted and an urgent transoesophageal echocardiogram was performed (top, transgastric view; MV, mitral valve; LV, left ventricle; LA, left atrium). This showed torrential mitral regurgitation secondary to a flail anterior mitral valve leaflet. The ruptured anterolateral papillary muscle could be identified attached to the leaflet via its chordae (arrowhead).

An intra-aortic balloon pump was inserted and coronary angiography performed. This revealed significant lesions in the left anterior descending (LAD) and right coronary arteries (RCA). At surgery the anterior mitral leaflet was confirmed to be flail but with chordae attached. The anterolateral papillary muscle had infarcted and torn off at the attachment to the ventricular wall (bottom, note the irregular discolouration of the infarcted muscle tip). The entire anterior leaflet was excised and replaced with a St Jude prosthesis. Vein grafts were placed on the LAD and RCA. He was discharged 10 days later.

Papillary muscle rupture is a rare but often fatal complication of myocardial infarction. Posteromedial papillary muscle involvement occurs more commonly than anterolateral papillary muscle involvement. These are usually secondary to full thickness inferior and anterolateral infarctions, respectively. Complete transection of a muscle causes catastrophic mitral regurgitation and is usually fatal.

P R KALRA

S K OHRI

J M MORGAN
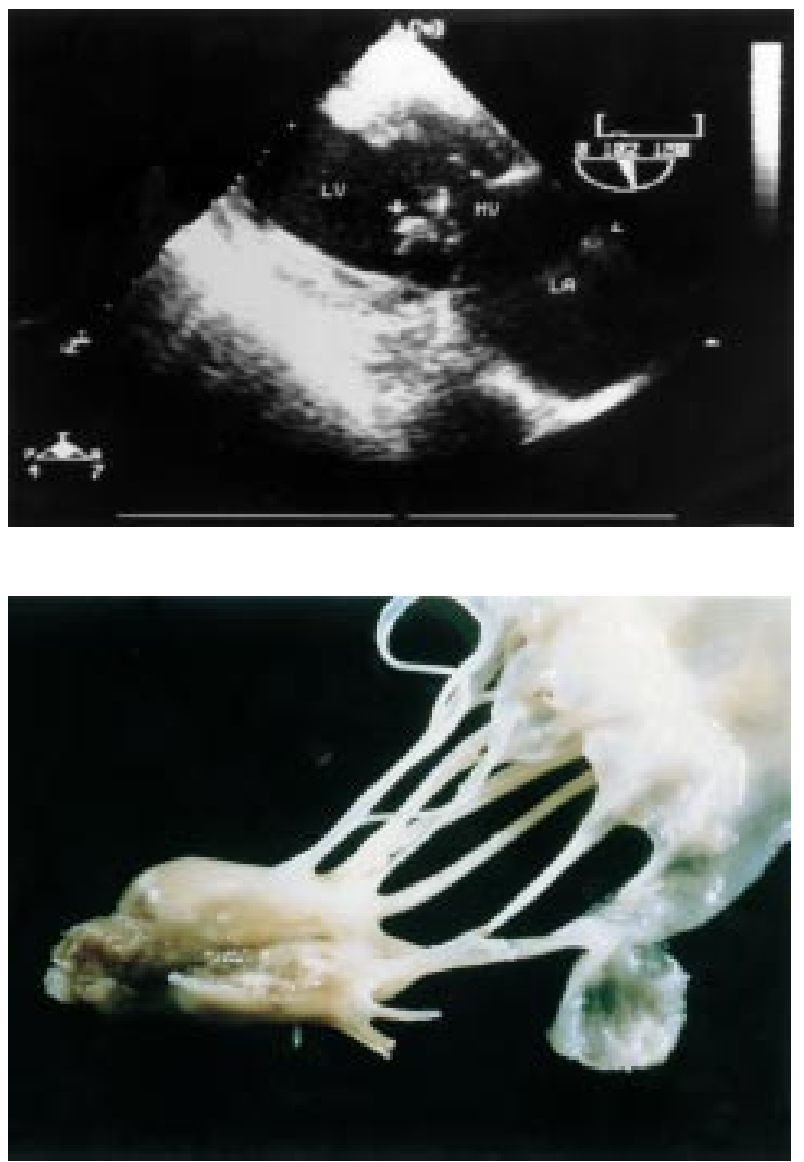